\title{
Guarda Compartilhada: As Vivências de Filhas Adolescentes
}

\author{
Camila Almeida Kostulski ${ }^{1}$ \\ ${ }^{1}$ Universidade Federal de Santa Maria, RS, Brasil.
}

\author{
Dorian Mônica Arpini ${ }^{1}$ \\ ${ }^{1}$ Universidade Federal de Santa Maria, RS, Brasil.
}

Resumo: O presente artigo apresenta os resultados de uma pesquisa qualitativa, a qual tem por objetivo compreender as vivências de guarda compartilhada do ponto de vista de filhas adolescentes. $\mathrm{O}$ método utilizado foi o de estudo de casos múltiplos. Integraram este estudo três famílias, com filhas adolescentes, com vivência de guarda compartilhada, cujos pais foram clientes do Núcleo de Assistência Judiciária, órgão vinculado a uma Instituição Pública de Ensino Superior, do sul do país. Como instrumento de coleta de dados, utilizou-se a análise documental nos prontuários dos clientes da instituição referida, o preenchimento de um formulário com os pais e com as adolescentes e uma entrevista semidirigida realizada com as adolescentes. A análise dos dados foi realizada segundo a técnica de análise de conteúdo. Os resultados indicam que as adolescentes vivenciam de forma satisfatória a guarda compartilhada, sendo esta avaliada como uma importante estratégia para a manutenção dos vínculos parentais após a dissolução conjugal. Destaca-se ainda, que as adolescentes apontaram algumas dificuldades vivenciadas nas relações com seus pais, entretanto, parece que estas não inviabilizam a vivência dessa modalidade de guarda.

Palavras-chave: Guarda Compartilhada, Adolescentes, Parentalidade, Relações Familiares.

\section{Joint Custody: The Experiences of Teenage Daughters}

\begin{abstract}
This article presents the results of a qualitative research that aims to comprehend the experiences of joint custody from the teenage daughters' point of view. The method chosen to conduct the study was multiple case study. The participants were three families, with teenage daughters, that had experienced joint custody, whose parents were clients in the Núcleo de Assistência Judiciária (Legal Assistance Center), an entity associated to a Public University located in the south of Brazil. A document analysis of clients' reports, the fulfilment of a form with both parents and adolescents and a semi-directive interview conducted with the teenage girls were used for data collection. Data analysis was based on content analysis. The results pointed out to a satisfactory experience with joint custody from the teenage girls' point of view, and to the evaluation of this category of custody as an important strategy for the maintenance of parents' bounds after a marital dissolution. It is emphasized that adolescents pointed out some difficulties in the relationships with their parents; however, it seems that these difficulties do not interfere in this type of custody.
\end{abstract}

Keywords: Joint Custody, Adolescents, Parenting, Family Relationships. 


\section{Custodia Compartida: Las Vivencias de Hijas Adolescentes}

Resumen: Este artículo presenta los resultados de una investigación cualitativa, cuyo objetivo es comprender las experiencias de custodia compartida desde el punto de vista de hijas adolescentes. El método escogido fue lo del estudios de caso múltiples. Han integrado este estudio tres familias, con hijas adolescentes, con experiencia de custodia compartida, cuyos padres han sido clientes del Núcleo de Asistencia Judiciaria, órgano vinculado a una Institución Pública de Educación Superior, del sur de Brasil. Como instrumento de recolección de datos, se utilizó el análisis documental en los prontuarios de los clientes de la institución referida, el llenado de un formulario con los padres y con las adolescentes y una entrevista semidirigida realizada con las adolescentes. El análisis de los datos fue realizado según la técnica de análisis de contenido. Los resultados indican que las adolescentes experimentan de forma satisfactoria la custodia compartida, siendo ésta evaluada como una importante estrategia para el mantenimiento de los vínculos parentales después de la disolución conyugal. Se destaca, todavía, que las adolescentes apuntaron algunas dificultades vividas en las relaciones con sus padres, sin embargo, parece que éstas no inviabilizan la vivencia de esa modalidad de custodia.

Palabras clave: Custodia Compartida, Adolescentes, Parentalidad, Relaciones Familiares.

\section{Introdução}

A guarda compartilhada é uma modalidade que surgiu na década de 1960, na Inglaterra, e foi implementada em vários países há algum tempo. A utilização desta modalidade começou a ser entendida, a partir de uma possível injustiça causada pela guarda unilateral, visto que, haveria uma desigualdade de tratamento para os pais e os filhos se a guarda fosse imposta somente ao pai ou a mãe. Por isso, nesta modalidade, atribui-se a ambos os pais o dever de educação e cuidado perante crianças e adolescentes (Moreira, 2014; Alvarenga. \& Clarismar, 2015).

Diante das reivindicações dos pais que não detinham a guarda, dos princípios da isonomia entre homens e mulheres, do melhor interesse da criança, além das transformações vivenciadas pela família contemporânea, com destaque para a maior participação dos pais não-guardiões, foi estabelecida a guarda compartilhada no Brasil. De acordo com alguns autores (Alves, Arpini, \& Cúnico, 2015; Dias, 2015; Rosa, 2015a), essa modalidade traria a possibilidade de reequilibrar os papéis parentais e garantir que sejam supridas as necessidades afetivas e emocionais dos filhos após o rompimento conjugal.

Nesse contexto, as teorias de gênero também trouxeram importantes contribuições no sentido de problematizar o lugar naturalmente endereçado as mães no que diz respeito a sua condição para mater- nar, aspecto que foi abordado por Badinter (1985) com relação ao mito do amor materno. O legado histórico com relação às diferenças entre homens e mulheres certamente teve influências na perspectiva que identificou na mulher - a mãe e consequentemente a detentora natural da guarda dos filhos em casos de dissolução conjugal. Dessa forma, parece ser importante destacar que tais aspectos não resultam apenas de uma definição biológica e sim de uma perspectiva que considera as relações de poder que se organizam no contexto das experiências históricas e culturalmente construídas e que por isso mesmo podem ser transformadas (Butler, 2003; Saffioti, 2001; Tilio, 2014).

No Brasil foram apresentados vários projetos de lei para a instituição da guarda compartilhada no ano de 2002, como: Projeto de Lei $n^{\circ} 6.350 / 2002$, Projeto de Lei $n^{\circ} 6.315 / 2002$, Projeto de Lei $n^{\circ} 6.960 / 2002$ e por último o Projeto de Lei no $7.312 / 2002$. No entanto, apenas em 2008 é que o Brasil instituiu a possibilidade legal dessa modalidade, sendo que anteriormente a essa data só existia no ordenamento jurídico a guarda unilateral. Esta modalidade ocorre quando um dos pais detêm a guarda do filho por sentença de homologação de acordo ou decisória em caráter definitivo. Cabe salientar que, o termo definitivo, em Direito de Família, não quer dizer "eterno" (no sentido de que nunca possa ser alterado), mas, sim, podendo ser revisto (Cezar-Ferreira, \& Macedo, 2016). 
Nessa direção, foi a partir daqueles projetos, que em 13 de junho de 2008, foi promulgada a Lei $\mathrm{n}^{\mathrm{o}} 11.698$ que prevê a possibilidade da guarda compartilhada tanto por acordo entre os pais quanto por determinação judicial. Esta lei alterou a redação dos artigos 1.583 e 1.584 do Código Civil para instituir e regulamentar a guarda compartilhada. É importante destacar, que nessa lei, o grande determinante da modalidade de guarda a ser estabelecida é o melhor interesse dos filhos, e esse aspecto, de modo geral, é o que rege o Direito de Família (Brito, 2007; Cezar-Ferreira, \& Macedo, 2016; Oliveira, 2015).

Conforme dados do Instituto Brasileiro de Geografia e Estatística entre os anos de 2000 e 2013 a opção pela guarda compartilhada cresceu no Brasil, mas a guarda unilateral materna ainda era considerada soberana nas disputas (IBGE, 2014). Cezar-Ferreira e Macedo (2016) colocam que em suas experiências clínicas, de mediação familiar e em perícias, a guarda compartilhada, antes da obrigatoriedade no Brasil, era solicitada por alguns pais com o intuito diferente da real intenção do compartilhamento e o efetivo entendimento acerca da criação dos filhos. Muitos daqueles solicitantes, teriam como objetivo evitar que o guardião se mudasse para outro país, levando o filho, bem como, livrar-se do pagamento de alimentos ou diminuí-los.

Dessa maneira, entendendo que a guarda compartilhada consiste em uma modalidade na qual os pais criam e educam os filhos de forma conjunta (Cezar-Ferreira, \& Macedo, 2016; Golse, 2014), e que tem como prioridade o melhor interesse da criança e do adolescente e não dos pais, em 22 de dezembro de 2014, foi implementada no ordenamento jurídico, a guarda compartilhada ou conjunta como uma modalidade obrigatória no Brasil. Esta modalidade só não pode ser aplicada quando comprovado casos de negligência, violência ou outras ações que estejam ferindo os direitos previstos no Estatuto da Criança e do Adolescente - ECA (Brito, \& Gonsalves, 2013; Lei No 8.069; Machado, 2015).

Nesse contexto, Brito, Cardoso e Oliveira (2010) consideram que a guarda compartilhada busca a possibilidade de o filho conviver com o pai e a mãe de forma a flexibilizar a convivência com cada um de acordo com as necessidades da prole. $\mathrm{O}$ filho reside com um dos pais, mas pode ver o outro com frequência, de modo que os pais estabeleçam um diálogo e decidam conjuntamente sobre aspectos cotidianos do filho como: escola, lazer, saúde, entre outros fatores que ponderarem ser relevantes, sem precisar colocar dias e períodos rígidos para cada um conviver com o filho. Pensando nesses aspectos, surgem alguns questionamentos sobre a aplicabilidade da nova lei da guarda compartilhada, visto que, pela sua obrigatoriedade ser recente, a descrição desta gera algumas divergências de opiniões e posicionamentos.

Diante desse cenário, a nova lei da guarda compartilhada apresenta vantagens e desvantagens, que dependem do contexto a qual está sendo aplicado (Machado, 2015). Primeiramente percebe-se que essa modalidade de guarda traz como vantagens a responsabilização de ambos os pais de forma equilibrada na criação e educação dos filhos. No entanto, existem algumas divergências quanto aos termos equilibrada e igualitária. Na nova lei, de 2014, o termo equilibrado tem sido utilizado no sentido de evitar uma divisão pautada em tempos iguais e rígidos de convivência, tendo como objetivo evitar períodos restritos a finais de semana, isso porque considerando essa uma relação de amor, não há hora e nem dia marcado para saber quando vai sentir saudade ou necessitar da presença e apoio do outro. Já a convivência igualitária seria quando o pai e a mãe dividem o tempo que cada um convive com o filho, ou seja, este reside, por exemplo, uma semana na casa da mãe e outra semana na casa do pai. Nesse sentido, há uma alternância de residência que é uma característica da guarda alternada (Machado, 2015; Oliveira, 2015; Rosa, 2015b).

Outro aspecto a ser considerado, e que ainda divide opiniões, é o fato de os filhos terem duas casas, a do pai e a da mãe. Alguns autores acreditam que isso dificulta a organização da rotina de crianças e de adolescentes, sendo assim, seria importante aplicar a guarda compartilhada com uma residência única (Oliveira, 2015). Há, no entanto, outra concepção que considera positivo que filhos de pais separados tenham duas casas, pois isso pode ajudá-los a entender que a separação dos pais nada tem a ver com eles e que essa realidade pode ser facilmente incorporada na vida dos filhos. As crianças geralmente têm uma boa capacidade de adaptação a essa nova situação, desde que estejam em um ambiente que lhes proporcione cuidado e carinho, como também, possivelmente tem a capacidade de perceber as diferenças de comportamento de cada um dos pais, o que as ajuda a afastar o fantasma da exclusão que, em geral, elas sentem em relação ao pai que não detém a guarda (Machado, 2015; Oliveira, 2015; Sodermans, \& Matthijs, 2014). 
Outro ponto de discordância, situa-se na necessidade ou não dos pais, após a ruptura conjugal, manterem um relacionamento harmonioso, pautado pelo respeito e o desejo de querer proporcionar uma melhor educação e um melhor atendimento as necessidades dos filhos. Percebe-se que minimizar possíveis conflitos decorrentes da dissolução conjugal pode auxiliar na qualidade do exercício das funções parentais, de modo que, o sofrimento do término da relação de conjugalidade não se sobreponha aos vínculos familiares (Rosa, 2015b). Desse modo, os filhos de pais que se separaram, que mantém o diálogo e conseguem ter uma boa relação, geralmente não precisam de regras e princípios sobre a guarda compartilhada, pois naturalmente já compartilham o cotidiano da prole. A lei parece ser necessária exatamente para aqueles que não conseguem estabelecer um diálogo, ou seja, para aqueles que possivelmente não conseguem manter um entendimento sobre a própria guarda dos filhos. Ressalta-se que mesmo em situações litigiosas não deveria ocorrer a suspensão do compartilhamento da guarda (Machado, 2015; Rosa, 2015b). Entretanto, isso só não será aplicado caso um dos pais declarar ao magistrado que não deseja a guarda do filho, sendo assim, instituída a guarda unilateral (Lei No 13.058; Machado, 2015). Nesse sentido, alguns juízes consideram que há uma incongruência quanto a descrição feita, isso porque, se a guarda compartilhada é entendida como benéfica ao filho, não seria indicado permitir que um dos pais a desfizesse, salvo em situações que ferem os direitos previstos no ECA (Lei No 8.069; Machado, 2015).

Diante desse contexto e com vistas a refletir e contribuir sobre essas questões, este estudo teve como objetivo compreender as vivências de guarda compartilhada do ponto de vista de filhas adolescentes.

\section{Metodologia}

\section{Delineamento}

Com o intuito contemplar os objetivos do estudo, foi realizada uma pesquisa de abordagem qualitativa e de caráter exploratório. Segundo Gaskel (2005), a pesquisa qualitativa fornece dados para a compreensão das relações entre os atores sociais e sua situação. Godoy (1995) e Gomes (2007), acrescentam que nessa abordagem os fenômenos são compreendidos a partir dos sujeitos envolvidos e que, a pesquisa qualitativa possui cunho exploratório, pois tenta entender a rea- lidade a partir das vivências subjetivas e dos significados atribuídos e não apenas de forma objetiva.

O método utilizado foi o estudo de casos múltiplos, que consiste na lógica da replicação. O estudo de cada caso em particular é analisado e discutido com os demais, de forma a constituir um caso completo. Destaca-se que a vantagem desse método consiste na possibilidade de aprofundamento da situação pesquisada (Yin, 2005).

\section{Cenário do estudo}

Este estudo foi realizado em um Núcleo de Assistência Judiciária, vinculado a uma instituição pública de ensino superior da região sul do Brasil. As atividades desenvolvidas no referido Núcleo são voltadas para áreas do Direito de Família e Civil, atendendo pessoas com renda mensal de até três salários mínimos. No ano de 2005 teve origem o projeto de extensão intitulado "Serviço de Psicologia junto ao Núcleo de Assistência Judiciária: uma orientação familiar", realizado pelo Departamento de Psicologia em parceria com o Núcleo de Assistência Judiciária. Esse projeto visa à articulação entre o Direito e a Psicologia na resolução de situações que envolvam conflitos na área do Direito de Família. Tal interlocução é entendida como de fundamental importância, visto que a ciência jurídica está repleta de aspectos de cunho psicológico e a prática de resolução de conflitos está permeada por questões subjetivas.

Inicialmente a prática do projeto envolvia a realização de atendimentos com quem buscou o serviço de assistência judiciária e também com a outra parte envolvida no conflito familiar. Em 2007, passou a ser realizado no projeto, a mediação familiar extrajudicial (Gaglietti, Araujo, \& Gaglietti, 2015), como uma ferramenta na resolução de conflitos. A partir do ano de 2014 o projeto passou a ter caráter de programa de extensão, devido ao seu tempo de existência na instituição e, além das práticas de atendimentos com os sujeitos envolvidos em conflitos familiares e de mediação familiar, deu-se início ao acompanhamento da guarda dos filhos após os acordos de separação, especialmente nos casos em que a modalidade de guarda compartilhada foi acordada. Essa atividade consiste em fazer contatos constantes com os envolvidos nos acordos, com o intuito de auxiliar os pais e mães no exercício da parentalidade, contribuindo para a manutenção permanente das responsabilidades parentais, que devem ser diferenciadas da dissolução da conjugalidade no momento da separação. 


\section{Instrumentos e procedimentos}

Para a realização da coleta de dados utilizou-se uma análise documental nos prontuários do Núcleo de Assistência Judiciária, incluindo os acordos estabelecidos entre os pais e os registros realizado pelo serviço de Psicologia. Além disso, foi feito o preenchimento de um formulário com os pais e com as adolescentes com a finalidade de atualizar os dados presentes nos prontuários e outras informações sobre o contexto familiar. O formulário dos pais contemplava itens, tais como: iniciais do nome, data de nascimento, naturalidade, telefone, endereço, número de dependentes, número de moradores, renda do(a) pai/mãe, renda familiar, tipo de residência, escolaridade, profissão, número de filhos e idade, local de trabalho, função, salário, recebe algum benefício, estado civil, recasamento (quantos), possui filhos (quantos), idade, tipo de guarda. Já no formulário dos adolescentes constou: iniciais do nome, data de nascimento, idade, sexo, estuda (qual ano), com quem reside, trabalha (faz estágio), renda, qual idade tinha quando seus pais se separaram.

E por último foram realizadas entrevistas semidirigidas (Turato, 2003) com as adolescentes participantes do estudo. O roteiro da entrevista buscou explorar aspectos referentes ao dia a dia das adolescentes; a separação dos pais e as vivências da guarda compartilhada; a relação de cuidado vivenciada pelas adolescentes por parte dos pais - decisões e responsabilidades; e por último as vivências nessa modalidade de guarda em datas especiais como aniversário dos pais, Natal, Ano Novo e férias escolares.

\section{Participantes}

Integraram este estudo três casos envolvendo famílias com vivência de guarda compartilhada, nas quais haviam filhas adolescentes. Também foi considerado como critério de inclusão uma vivência de no mínimo seis meses nessa modalidade para que pais e filhas pudessem estabelecer uma rotina diante da aplicação da guarda compartilhada.

Além disso, as famílias que participaram do estudo procuraram o Núcleo de Assistência Judiciária de uma Universidade Federal do sul do país, no período posterior a 2008. Ou seja, após a implementação da Lei ${ }^{\circ}$ 11.698, de 13 de junho de 2008, a qual coloca a guarda compartilhada como uma das modalidades de guarda no Brasil. As adolescentes participantes, foram do sexo feminino, com idades entre 12 e 18 anos incompletos, critério estabelecido de acordo com o ECA (Lei No 8.069).
A escolha por adolescentes, deu-se pelo fato de que muitos destes, apesar de estarem em período de desenvolvimento, já conseguem ter um posicionamento sobre os sistemas sociais e propor novas formas de conduta, discutir valores morais de seus pais e possivelmente, construir os seus próprios valores (Fiori, 1981-1982; Piaget, 2010).

A seguir, apresenta-se uma síntese dos casos.

\section{Caso Nina: descrição da história familiar}

Ana e João foram casados por 28 anos e têm três filhos: duas meninas e um menino. Em 2014, Ana decidiu se separar de João, via divórcio, motivo pelo qual refere ter procurado o Núcleo de Assistência Judiciária para realizar a ação. Com o pedido de divórcio Ana solicitou o estabelecimento da guarda e o pagamento da pensão alimentícia. Constam nos documentos, que o caso foi avaliado pela equipe do serviço, composta por acadêmicos da Psicologia e do Direito e uma Assistente Social e, foi sugerido aos clientes uma mediação familiar extrajudicial, na tentativa de um acordo entre o ex-casal. Os registros nos prontuários indicam que, foi acordado que a guarda ficaria na modalidade compartilhada, sendo explicado tanto para Ana como para João como era o funcionamento desta, como também, foi estipulado a pensão, as visitas e que os filhos teriam como residência fixa, a casa da mãe.

\section{O Relato de Nina}

Nina é uma menina de 13 anos, cursa o sétimo ano e vivenciou a separação dos pais quando tinha 11 anos. A adolescente relata que ficou sabendo da separação dos pais pela sua mãe, sendo explicado para Nina, que ficaria morando um período com a mãe e outro com o pai. Atualmente, reside com a mãe e, geralmente, visita o pai nos finais de semana, tendo uma boa relação com ambos. Nina declara que o pai paga pensão, mas que escola, médico e outras atividades cotidianas ficam a cargo da mãe. A adolescente pondera que o pai não frequenta muito sua casa devido ao novo companheiro da mãe, e que ela, por ter mais contato com a mãe, a autorização para realizar algo é tomada, na maioria dos casos, por esta.

Em datas como, aniversário dos pais, Nina refere que sempre passa com seu respectivo genitor; as férias escolares, a adolescente alterna entre pai e mãe e, no último Natal e no Ano Novo preferiu passar ambos com a mãe. Por fim, a adolescente relata que a guarda 
compartilhada não é difícil e funciona na família dela, pois refere que não tem problemas em alternar entre a casa do pai e da mãe.

\section{Caso Mel: descrição da história familiar}

Antônio e Marta tiveram uma união estável por 17 anos e após brigas e tentativas de reconciliação decidiram se separar. Eles têm uma filha de 12 anos, que após a separação passou a residir com a mãe. Ao procurar o Núcleo de Assistência Judiciária, Marta tinha como demanda a legalização da separação, definição de guarda, pensão alimentícia e divisão de bens. Nos prontuários do serviço, constam que a partir da avaliação da equipe foi sugerido que eles pudessem discutir os pontos trazidos, primeiro separadamente posteriormente em conjunto em uma mediação familiar. Na mediação, foi acordada a dissolução da união estável, a guarda da filha, que ficaria na modalidade compartilhada, com residência fixa na casa da mãe e visitação livre do pai, sendo também, estabelecido o valor da pensão alimentícia e a divisão dos bens.

\section{$O$ relato de Mel}

Mel é uma menina de 14 anos, cursa o sétimo ano e é filha única. A adolescente relata que mora com a mãe após a separação dos pais, pois, Marta não tem um bom relacionamento com a nova companheira do pai e também, porque o pai mora com seus avós, e Mel tem uma relação conflitiva com o avô. A adolescente refere que não teria problemas em conviver com a madrasta, mas tem receio de que sua mãe se sinta traída, e assim, encontra o pai em outros locais que não seja a casa dele. Quando seus pais se separaram, Mel ficou sabendo através da mãe esse fato, e acrescenta que quando precisa de autorização para realizar alguma atividade pede para esta, como também, fica a cargo da mãe, as reuniões da escola, médicos, dentre outras atividades cotidianas; o pai ajuda mais de forma financeira.

Para a adolescente, a relação dos pais é difícil, conflitiva, e ela refere que gostaria que eles fossem amigos. Em datas como o aniversário dos pais, ela passa com seu respectivo genitor. Nas férias escolares, Mel continua na casa da mãe e vê o pai com frequência. No último Natal e no Ano Novo ela iria passar uma das datas com o pai (este não tinha a nova companheira) e outra com a mãe, mas o pai foi viajar e a adolescente ficou em ambas as datas com a mãe. Por fim, Mel relata que ela gostaria que os pais pudessem ter uma relação mais harmoniosa e que ela pudesse frequentar as duas casas.

\section{Caso Fani: descrição da história familiar}

Vera e Jorge tiveram uma união estável de sete anos e tem uma filha que, atualmente, está com 12 anos. Consta nos prontuários que em 2009, Vera foi até o Núcleo de Assistência Judiciária para legalizar a separação, pois já não estavam juntos há um mês, como também, o estabelecimento da guarda da filha, as visitas e a pensão alimentícia. A equipe do serviço, após avaliar a situação sugeriu ao ex-casal realizassem uma mediação familiar para um possível acordo entre eles. Como Vera e João pareciam estar convictos de suas decisões e também pelo bom relacionamento entre eles, a mediação transcorreu de forma tranquila, porque eles já vieram com um pré-acordo. Ficou acordada a dissolução da união estável, a guarda da filha, que ficou na modalidade compartilhada, com fixação da residência com a mãe, visitação livre do pai, e também, foi estabelecido o valor da pensão.

\section{O Relato de Fani}

Fani tem 12 anos e cursa o sexto ano escolar. Quando seus pais se separaram ela tinha seis anos e relata ter tido dificuldades em saber da separação, pois o pai dizia para ela falar com a mãe sobre o assunto e a mãe vice-versa. A mãe de Fani tem um novo companheiro e foram eles que lhe explicaram o que era guarda compartilhada. Segundo o que a adolescente entendeu, ela moraria com a mãe, e quando o pai quisesse vê-la, ele entraria em contato com a mãe para combinarem. Fani mora com a mãe e não tem dias estabelecidos para visitar o pai, e sim quando eles desejarem. Quanto à autorização para realizar alguma atividade, ou quando precisa ir ao médico, ou ainda, em reuniões escolares, isso fica a cargo da mãe.

Em datas como o aniversário dos pais, ela passa com o respectivo genitor e nas férias escolares ora fica com a mãe, ora com o pai, alternadamente. Em datas como Natal e o Ano Novo, Fani diz que passa a noite de Natal com a mãe, isso quando sua madrinha vem de XZ [local referido pela adolescente]; e almoça na casa do pai. Quando a madrinha não vem, ela passa o Natal com o pai e Ano Novo com a mãe, porque suas primas posam na casa dela. Além disso, Fani relata ter um bom relacionamento tanto com o padrasto como com a 
madrasta. Por fim, a adolescente coloca que na família dela há uma vivência de guarda compartilhada, visto que, o pai pode buscá-la na casa da mãe sempre que combinado e compartilham momentos juntos.

\section{Análise dos dados}

Num primeiro momento, foi realizada uma análise de cada caso, de forma detalhada para que fosse possível construir um estudo aprofundado de cada adolescente e seu contexto familiar. Após esse primeiro momento, foi feita uma análise cruzada dos casos com o intuito de encontrar pontos similares ou singulares entre os casos (Yin, 2005). O procedimento de análise utilizado, foi a análise de conteúdo proposta por Bardin (2010).

\section{Considerações éticas}

Este estudo atendeu a todas as exigências da ética em pesquisa segundo as Diretrizes e Normas Regulamentadoras envolvendo Seres Humanos - Resolução no 466/2012 do Conselho Nacional de Saúde, como também, a Resolução no 016/2000 do Conselho Federal de Psicologia. A pesquisa obteve aprovação do Comitê de Ética em Pesquisa da Universidade em que foi realizado, sendo aprovado sob CAAE 50645515.0.0000.5346. Além disso, tanto as participantes como seus responsáveis ficaram cientes do objetivo do estudo, os responsáveis assinaram o Termo de Consentimento Livre e Esclarecido e as adolescentes, o Termo de Assentimento Livre e Esclarecido. Por fim, com o objetivo de preservar a identidade das participantes e suas famílias, os nomes aqui apresentados são fictícios.

\section{Resultados e Discussão}

Os resultados deste estudo são apresentados em duas categorias. A primeira está intitulada "Guarda compartilhada: o cotidiano vivenciado pelas adolescentes", que tem como foco discutir as vivências de guarda compartilhada enfatizando a experiência relatada pelas adolescentes em suas famílias, identificando aspectos presentes na legislação e relacionando-os com os seus cotidianos.

A segunda categoria tem como título "Superando obstáculos: as dificuldades enfrentadas pelas adolescentes nas vivências de guarda compartilhada", esta categoria aborda as principais dificuldades vivenciadas pelas adolescentes em suas vivências de guarda compartilhada, salientando que mesmo diante des- tas, a aplicação dessa modalidade não se torna inviável, nas famílias do estudo.

\section{Guarda compartilhada: o cotidiano vivenciado pelas adolescentes}

A guarda compartilhada mesmo sendo implementada em 2008 no Brasil e, obrigatória em 2014, pode ser considerada recente no país. Esta modalidade veio como uma possível estratégia para tentar solucionar a ausência paterna (Cúnico, 2014; Cúnico, \& Arpini, 2013; Sganzerla, \& Levandowski, 2010), ou materna diante da separação conjugal.

A partir da análise dos casos que compõe este estudo, observa-se que Nina e Fani, parecem ter, minimamente, conhecimento sobre o que é, ou como funciona a guarda compartilhada. Esse conhecimento foi transmitido, possivelmente, pela família. Isto pode ser visto no discurso de Nina: "ahh eles me falaram que daí eu ia ficar um pouco com a minha mãe, com meu pai". E também no relato de Fani: "que daí quando meu pai quiser me pegar, é só ele ligar e pedir para me pegar e ver quando pode. E daí ele pode me pegar". Nesses fragmentos pode-se pensar que mesmo de forma simples estas adolescentes parecem entender 0 verdadeiro propósito da guarda compartilhada, considerando o contexto sociocultural e familiar de cada uma. Com isso, na fala de Fani, percebe-se certa flexibilidade nos momentos em que o pai pode visitá-la, como também, para buscar a adolescente para ir à sua casa ou realizar alguma atividade conjunta. Esta colocação vem ao encontro do que está proposto na nova lei da guarda compartilha, uma vez que, o tempo de convivência com os pais deve ser equilibrado.

Ainda pensando no tempo de convivência equilibrado dos pais, quando questionado às adolescentes como elas e seus pais organizavam algumas datas comemorativas como Natal e Ano Novo, pode-se ressaltar a fala de Fani.

Quando a minha "dinda" vem de WZ [local referido pela adolescente] eu passo a noite com a minha mãe e no outro dia vou para casa do meu pai, isso no Natal e no Ano Novo também. E quando ela não vem eu passo o Natal com o meu pai e o Ano Novo com a minha mãe, porque no Ano Novo minhas priminhas vão posar lá em casa [...]. Um pouco na casa de cada um, às vezes, eu viajo com um, as vezes com o outro; as vezes com os dois só que separados (Fani). 
Nesse relato, pode-se inferir que, no caso de Fani, não haveria uma divisão de tempo nessas datas comemorativas, uma vez que, parecem estar organizadas de forma flexível de acordo com a disponibilidade do pai e da mãe e, principalmente, adaptada a aspectos do cotidiano, como a visita das primas e da madrinha da adolescente. Assim, é importante destacar que essa organização parental, de guarda compartilhada, não visa uma estrutura rígida quanto ao tempo de convivência materna e paterna. Para Brito (2007) e Rosa (2015b) na guarda compartilhada o que importa é que as decisões a respeito da vida da prole sejam tomadas em conjunto entre os pais.

Nesse contexto, no relato de Nina, a adolescente refere que passou o Natal e o Ano Novo com a mãe, que é com quem ela reside. Como mostra o trecho a seguir: "é os dois com a minha mãe, com o meu pai eu não fiquei”. Ao deter-se nesse fragmento, em um primeiro momento, poder-se-ia inferir que nessa família haveria uma certa dificuldade com a flexibilidade e o equilíbrio de tempo em que a adolescente convive com seus pais. Entretanto, pensando de uma forma mais ampla, e analisando os relatos subsequentes, entende-se que o fato de, nesse caso, não haver uma divisão equilibrada de tempo, não implica que isso não ocorra em outras ocasiões, de acordo com o desejo de Nina, como foi relatado pela adolescente quando questionada a respeito do motivo pelo qual não visitou/ficou com pai em uma das datas. A adolescente diz: "ah eu queria ficar com a minha mãe". Ressalta-se isso, para que se possa pensar que a maneira como uma família se organiza diante da guarda compartilhada é singular, considerando que, muitas vezes, o que funciona para um contexto familiar, não contempla o outro (como se pode ver nos dois relatos até aqui apresentados). No entanto, é importante mencionar que há algumas características que são indispensáveis quando se aplica a modalidade de guarda compartilha, mas isso não impede que a forma como cada família vai adaptar os aspectos legais a sua realidade social e familiar podem ser diferentes, e isso não significa que a guarda compartilhada não estaria levando em conta o superior interesse dos filhos.

Outro fator que merece ser destacado, é a busca pela flexibilidade da relação parental nas vivências de guarda compartilhada. Essa flexibilidade contemplaria adequar as atividades de pai, mãe e filhos para que a participação daqueles possa ser atrelada a aspectos práticos da vida destes. Isso pode ser melhor compre- endido a partir do relato de Fani, quando questionada a respeito de quem vai à escola quando solicitada a presença do responsável, a adolescente relata que: "as vezes vai a mamãe, e é raro ser o papai [...]”. E em outro momento Fani explica: "é porque a mamãe mora mais perto da escola”. Diante disso, sabe-se da importância da participação e da responsabilização tanto materna quanto paterna na vida dos filhos (Sodermans, \& Matthijs, 2014), entretanto, é importante ponderar que a modalidade compartilhada é o ideal de guarda e que dessa forma, possivelmente, sejam necessárias algumas adaptações considerando a realidade de cada família e alguns empecilhos de ordem prática. Por um lado, salienta-se que, utilizando o exemplo de Fani, algumas ações são adaptadas com o intuito de facilitar o cotidiano dos pais. Nesse sentido, pode-se inferir que o horário e a distância da casa do pai, em relação à escola, pode ser um fator dificultador e que possivelmente faça com que seja mais viável a presença da mãe. Por outro lado, esses empecilhos não podem impedir que em determinados momentos o pai possa se organizar de forma que se faça presente no ambiente escolar.

Nessa mesma direção, a participação paterna é referida pelas adolescentes como sendo a figura do pai provedor, isso pode ser observado quando as participantes relatam, que de forma geral, o pai ficaria responsável pela parte financeira. No entanto, o que se pode compreender é que os pais não teriam se restringido apenas a essa atribuição, ampliando sua participação no cotidiano das filhas. Com isso, pode-se inferir que a guarda compartilhada, possivelmente, tenha contribuído nesse sentido.

A partir dos casos que compõe este estudo, entende-se que uma boa comunicação entre os pais é importante para a vivência da guarda compartilhada, uma vez que, de acordo com o exemplo citado anteriormente, na impossibilidade da participação do pai nas atividades escolares de Fani, a mãe poderia informá-lo sobre os assuntos discutidos nesse ambiente. Sabe-se que após a dissolução conjugal, muitos pais apresentam dificuldades para dialogar a respeito dos filhos. No entanto, a ausência de uma boa comunicação não deve ser considerada uma justificativa para o distanciamento e uma possível desresponsabilização parental. Nesses casos é necessário que pais e mães superem os ressentimentos advindos do divórcio, e aos poucos, priorizem a relação com os filhos. Este processo, geralmente não é considerado fácil, entre- 
tanto, serão necessários esforços de ambas as partes para que os filhos não sejam alvo de uma ação que diz respeito somente aos pais. Com o intuito de minimizar essa situação, muitos pais podem necessitar da ajuda de profissionais, para ultrapassarem essas dificuldades, que muitas vezes, parecem complexas, mas que com ajuda poderiam ser minimizadas ou solucionadas. Nesse ínterim, para Cezar-Ferreira e Macedo (2016) e Lehman (2013) ter filhos, independentemente da situação conjugal, requer investimentos para além de questões financeiras, como esforços cotidianos que fazem a manutenção de vínculos afetivos e de cuidado.

Outro ponto que pode repercutir nas vivências da guarda compartilhada e que pode gerar algumas divergências é a fixação de residência, visto que, nessa modalidade é possível que o filho tenha uma residência fixa, mesmo sob a responsabilidade de ambos pais. Nos casos que integram esse estudo, as adolescentes moram com as mães, mas isso não implica em que estas tenham a responsabilidade exclusiva daquelas. Uma das adolescentes, Nina, destacou que a possibilidade de poder frequentar a casa do pai e da mãe é um fator considerado positivo; como pode ser visto no relato da adolescente: "porque eu gosto de ficar numa casa e na outra". E ainda quando questionada como é ter duas casas, a adolescente menciona que "não tem problema".

Autores como Brito (2004) e Rosa (2015b) destacam que apesar das divergências de opiniões, ter duas residências pode ser considerado um fator positivo, pois mostraria aos filhos que a separação dos pais não tem relação com aqueles, e que essa é uma experiência que pode ser incorporada na vida da prole. Brito (2003) argumenta que da mesma forma que os filhos conseguem entender, gradualmente, a rotina da escola, da creche, da casa dos avós, por exemplo, eles também usariam dessa capacidade para se adaptar a casa do pai e da mãe, desde que esses ambientes representem um espaço de cuidado e afeto.

Diante desse panorama, pode-se perceber que mesmo a lei da guarda compartilhada sendo recente, esta tem possibilitado que modificações nas relações entre pais e filhos após a separação conjugal já possam ser vivenciadas, mesmo que de forma gradual. Para alguns pais, ou até mesmo para muitos, esse modelo não é tão conhecido e usual, mesmo assim, alguns buscam se esforçar para manter uma relação de cuidado e afeto com os filhos. Esse possível investimento na busca pela vivência de guarda comparti- lhada, pode-se observar no relato de Nina: "eu acho que funciona, né, e é fácil".

Entende-se, que o termo "fácil", pode ser considerado de grande impacto no relato de Fani, visto que, sabe-se das dificuldades enfrentadas pelas maiorias dos pais. No entanto, pode-se pensar que a adolescente parece querer dizer da possibilidade de vivenciar essa modalidade de guarda mesmo diante de algumas dificuldades. Além disso, a adolescente reforça um dos principais objetivos da guarda compartilhada, que é a possibilidade de ambos os pais estarem presentes no cotidiano dos filhos, de forma a se responsabilizarem conjuntamente por estes.

$O$ relato a seguir, pode ser um exemplo, mesmo que simples, da essência dessa modalidade, quando Nina diz: "ah, mas é bom assim, eu fico com a minha mãe, com o meu pai”. No decorrer da análise desse caso, destaca-se que quando a adolescente coloca que ela pode ficar com o pai e com a mãe, ela parece estar se referindo muito mais que simplesmente poder frequentar o lar materno e paterno, mas sim, o fato de que mesmo diante de possíveis sofrimentos que uma ruptura conjugal pode trazer, a adolescente sente que os pais estão presentes na sua vida, não somente em tempo de convivência, mas sim, de forma que Nina perceba, mesmo que aos poucos, ações que envolvam, cuidado, afeto, respeito, ou seja, que ela entenda que os pais, de fato, exercem suas funções.

Nesse cenário, Gadoni-Costa, Frizzo e Lopes (2015) salientam que a separação conjugal não pode diminuir o desejo do pai e da mãe em exercer a sua função e continuar próximo dos filhos, entretanto, para que isso ocorra, é necessário que haja certa flexibilidade na relação com os filhos, com a ex-mulher ou ex-marido e, até mesmo, consigo mesmo, no sentido de dar tempo para que as adaptações aconteçam.

\section{Superando obstáculos: as dificuldades enfrentadas por adolescentes nas vivências de guarda compartilhada}

A guarda compartilhada por ser uma modalidade ainda pouco usual no ordenamento jurídico brasileiro (IBGE, 2014), acaba por apresentar alguns obstáculos em suas vivências. Pensando nisso, nos casos analisados nesse estudo, uma das adolescentes parece ter tido dificuldades em poder descrever o que seria a guarda compartilhada, a partir do momento em que foi questionada sobre como seus pais explicaram sobre essa modalidade. Isto pode ser exemplificado 
no fragmento a seguir: "não sei, tipo, não sei explicar muito bem". Mas em outro momento a adolescente acrescentou "[...] que eu pudesse ficar nas duas casas, tipo uma semana na casa da minha mãe e a outra na do meu pai [...]. O relato de Mel parece refletir uma certa dificuldade em diferenciar a guarda compartilhada da guarda alternada, aspecto que, muitas vezes, faz-se presente também no discurso de pais e profissionais. Cezar-Ferreira e Macedo (2016) colocam que no início do século XXI, costumava-se identificar a guarda alternada com guarda compartilhada como se fosse uma só, contudo, a última tem sido entendida como a guarda ideal, pois busca atender o melhor interesse dos filhos.

A partir dessa discussão, a fala de Mel, citada anteriormente, permite refletir a respeito de como a adolescente compreendeu o relato de seus pais sobre a guarda compartilhada. Este aspecto é significativo na medida em que, se esta modalidade não está clara para os pais, pode dificultar o entendimento dos filhos e consequentemente a vivência da guarda compartilhada. Autores como Gadoni-Costa, Frizzo e Lopes (2015) e Cezar-Ferreira e Macedo (2016) enfatizam que muitos adultos, precisam de ajuda e de esclarecimentos para melhor definir e explicar aos filhos sobre a guarda compartilhada.

Ao sair dos aspectos mais conceituais e de entendimento das adolescentes sobre a guarda compartilhada, adentra-se nas vivências das adolescentes, as quais destacaram alguns aspectos a serem superados e que no momento parecem estar dificultando, mas não seriam impeditivos da vivência de guarda compartilhada.

Uma das adolescentes, Fani, menciona que ter duas residências, uma da mãe e outra do pai, talvez não seja um fator negativo, no entanto, relata que: "só é ruim quando eu estou em casa e o papai quer me pegar na escola, que daí eu tenho que levar a mochila com a roupa [...] Eu tenho poucas coisas na casa do meu pai". A partir disso, Oliveira (2015) aponta que ter duas residências acaba por desorganizar a vida e a rotina dos filhos, mas essa é uma opinião que apresenta certas divergências, já esboçadas anteriormente.

No entanto, Mel apresenta um contexto um pouco diferente quanto a ter duas residências, visto que ela não costuma frequentar a casa do pai. Isso acontece devido ao fato de que a mãe da adolescente não tem uma boa relação com a nova companheira do pai e, também, por Mel apresentar questões conflitivas com o avô paterno, com quem seu pai reside.
Assim, quando a adolescente foi questionada sobre o motivo pelo qual ela não costuma frequentar a casa do pai, a adolescente relata que é devido "ao meu avô e a mulher do meu pai”. Diante desses relatos, percebe-se que mesmo com alguns empecilhos, esse aspecto não é um fator que aparentemente prejudique a vivência da guarda compartilhada, desde que, os pais estejam disponíveis para encontrar alternativas para minimizar ou solucionar esses problemas. Para Gadoni-Costa, Frizzo e Lopes (2015), embora as dificuldades estejam presentes no cotidiano dessas famílias, aquelas estão presentes também em outras modalidades de guarda. O importante é que pais e mães possam estar envolvidos e participar da vida dos filhos, com o intuito de que os novos arranjos sejam bem-sucedidos e as dificuldades superadas. Cabe destacar, que embora a perspectiva desse artigo não se propôs a abordar o tema a partir das teorias de gênero, elas certamente têm um papel preponderante no que diz respeito a construção de novas modalidades de exercício parental, por terem lançado questões e problematizações com relação as experiências de homens e mulheres e suas relações com os filhos, como decorrentes de construções histórico-sociais e culturais e, portanto, mutáveis (Butler 2003; Saffioti, 2004).

Outro aspecto destacado, é a possibilidade da aplicação da guarda compartilhada mesmo com uma relação conflitiva entre os pais. Mel quando questionada sobre como está à relação dos pais diante das vivências de guarda compartilhada, relata: "é difícil, porque todo mundo é inimigo. Eu queria eles amigos, porque eu não quero, eu não gosto dessa situação". Nesse aspecto questiona-se sobre a possibilidade de a guarda compartilhada somente ser aplicada quando os pais apresentarem um relacionamento harmonioso. Brito e Gonsalves (2013) realizaram uma pesquisa junto aos acórdãos emitidos por três tribunais de Justiça do país no período entre 2008 e 2010. O objetivo foi estudar a maneira como a jurisprudência, emitida por alguns tribunais brasileiros, vem considerando a possibilidade de aplicação da guarda compartilhada. Dentre os resultados obtidos destaca-se a suposição de que essa modalidade não funciona quando há litígio entre os pais, e que a mesma seria fonte de desavenças entre os genitores.

Apesar desses resultados, entende-se que a relação harmoniosa entre o ex-casal facilitaria o convívio entre pais e filhos, mas não pode ser um fator determinante para a definição da atribuição 
da guarda compartilhada. Os dados da pesquisa referida são importantes para que se possa pensar novas formas de intervenção, especialmente da Psicologia, de modo a refletir sobre essa problemática que, muitas vezes, gera divergências de opiniões por parte de alguns profissionais.

No Brasil, principalmente depois da implantação da guarda compartilhada como obrigatória, muito se questiona sobre a aplicação dessa modalidade mesmo em caso em que os pais apresentam uma relação conflitiva posterior a separação. Autores como Rosa (2015a;b), Pereira (2011), Machado (2015), Brito e Gonsalves (2013) e Cezar-Ferreira e Macedo (2016) colocam que muitas das separações resultam em uma possível dificuldade no exercício da maternidade e paternidade em função de um misto de sentimentos que se fazem presentes, como: raiva, mágoa e sofrimento, que acabam interferindo no relacionamento com os filhos. Os autores entendem que esse é um momento difícil para os pais, mas salientam que é importante ter presente, que mesmo diante das dificuldades, os filhos devem ser a prioridade, visto que, a relação que se dissolveu foi a conjugal e não a parental.

Oliveira e Matos (2014) acrescentam que nas relações as quais os pais conseguem estabelecer o diálogo, expressam valores comuns para os filhos na tomada de decisão, participam dos cuidados cotidianos, não seria necessária uma lei de obrigatoriedade, como a da guarda compartilhada, pois naturalmente os pais já realizam ações conjuntas. A lei viria justamente para aqueles pais que apresentam uma relação de conflito.

Diante desse contexto, pode-se pensar que a divergência de opiniões e as dificuldades enfrentadas por filhas, neste caso adolescentes, também estão presentes no momento em que diante da aplicação da guarda compartilhada um dos pais acaba indo para outra cidade. Uma das adolescentes do estudo, Mel, relata que "única coisa que eu sei, que ele me contou [pai], é que ela mora em XZ [cidade da nova companheira], mas aí eu não sei mais nada". Nesse relato da adolescente, não fica tão claro que o pai da mesma vai morar em outra cidade com a nova companheira, entretanto, nos registros dos prontuários consultados, consta que há essa possibilidade. Independente disso acontecer, a ideia a se refletir é, que mesmo o pai indo morar em outra cidade, esse fato por si só, não tornaria inviável a aplicação da guarda compartilhada.

Machado (2015) e a Lei № 13.058 colocam que nos casos em que os pais residam em cidades dife- rentes, busca-se um consenso quanto à cidade base (onde o filho irá morar) que contemple os interesses do mesmo. Os autores ainda acrescentam que tal situação não impede a aplicação da guarda compartilhada, uma vez que, essa preza pela divisão de responsabilidade entre os genitores e no que se refere às decisões importantes na vida do filho e não sua presença física (mesmo sabendo de sua importância). Assim, entende-se que mesmo diante da distância física, as decisões conjuntas podem ser tomadas, principalmente levando em consideração o avanço tecnológico dos meios de comunicação.

Por fim, entende-se que essas são algumas das dificuldades relatadas pelas adolescentes em suas vivências de guarda compartilhada e que, apesar da presença destas em seu cotidiano, as mesmas parecem não estar sendo vistas como impeditivo para a vivência da guarda compartilhada.

\section{Considerações finais}

A partir da análise dos casos que integraram este estudo, percebe-se que a guarda compartilha pode ser considerada uma modalidade que possibilita a continuidade da convivência dos filhos com ambos os pais após a dissolução conjugal. Contudo, entende-se que por se tratar de um ideal, faz-se necessário algumas adaptações de acordo com cada contexto familiar, de modo que, a guarda compartilhada possa ser vivenciada, e ao mesmo tempo não perca sua essência.

As experiências nessa modalidade estão permeadas por algumas dificuldades, no entanto, para as adolescentes, essas dificuldades não parecem ser um grande problema, visto que, a guarda compartilhada é representada como uma vivência possível para elas. Nos casos que compõe este estudo, os pais parecem conseguir, cotidianamente, buscar a manutenção e o fortalecimento dos vínculos parentais, tendo em vista a importância da participação de ambos no cotidiano das filhas, de forma responsável e afetiva.

Por se tratar de um estudo de casos múltiplos, a limitação desta pesquisa consiste em apresentar um número reduzido de casos com essa vivência de guarda compartilhada. Com isso, destaca-se que não se teve a intenção de generalizar os resultados aqui apresentadas, mas de apontar algumas singularidades contidas nesses casos envolvendo a guarda compartilhada. Compreende-se, todavia, que os resultados obtidos nesta pesquisa, podem colaborar para o mapeamento de outras possíveis dificuldades que 
possam surgir nesse contexto, como também, para difundir aspectos positivos que vêm ganhando efetividade e que podem ser partilhados para outras famílias com guarda compartilhada.

Destaca-se, ainda, que este estudo pode ser uma forma de inspirar outros pesquisadores a desenvolver trabalhos que tenham como foco a guarda compartilhada. Como também, que pais e profissionais que trabalham com essa temática possam refletir que mesmo diante de algumas dificuldades, essa modalidade, tem o potencial de evitar a ausência de um dos pais no exercício da parentalidade após a dissolução conjugal. Os impasses que muitas famílias vivenciam após a separação conjugal são conhecidos, contudo, destaca-se que ser mãe e ser pai, são funções que devem se manter e se sobrepor às rupturas amorosas do par conjugal. Nesse sentido, estudos que abordem a temática da guarda compartilhada a partir da perspectiva das teorias de gênero, podem ser importantes contribuições na ampliação, aprofundamento e compreensão da sua aplicabilidade, levando em consideração a relevância dessa perspectiva.

A Lei $\mathrm{n}^{\circ} 13.058$ de 2014 coloca algumas características que norteiam a obrigatoriedade da guarda compartilhada no Brasil. Entretanto, pensando que esta é uma lei recente, muitos pais, filhos e profissionais, ainda buscam se adaptar a essa nova legislação de forma que possam pensá-la e adaptá-la no contexto de cada família. Ressalta-se que para que os pais possam vivenciar, de fato, a guarda compar- tilhada, é necessário que os profissionais que trabalham com famílias, como: Psicólogos, Operadores do Direito, Assistentes Sociais, dentre outros, saibam informar de forma clara, como funciona esta modalidade, auxiliando as famílias a encontrar pontos de acordo e negociação de conflitos, pois só assim, ela poderá ser concretizada satisfatoriamente, com vistas ao bem-estar e ao cuidado dos filhos, em forma de vivências positivas e que promovam o desenvolvimento integral.

Por fim, a partir dos resultados desse estudo, entende-se a importância do acompanhamento Psicológico, em casos que se faça necessário, para as famílias em vivências de guarda compartilhada. Para além das intervenções individuais desse núcleo profissional, considera-se importante que a Psicologia possa desenvolver intervenções juntamente com Operadores do Direito, Assistentes Sociais e outros profissionais, com intuito de auxiliar as famílias quanto as possíveis demandas decorrentes da separação conjugal, tendo em vista, a minimização dos conflitos familiares. Nesse sentido, pode-se desenvolver intervenções como oficinas de parentalidade com mães e pais que estejam ou estiveram em processo de separação, como também, realizar mediações de conflitos familiares, grupo multiparentais ou psicoeducativos entre outros. Essas estratégias podem auxiliar a trabalhar possíveis sofrimentos advindos do momento de ruptura familiar, fazendo uma interlocução entre os fazeres psicológicos e de outros núcleos profissionais.

\section{Referências}

Alvarenga, A. R., \& Clarismar, J. (2015). Sistemas de guarda no direito brasileiro. Revista do Curso Direito UNIFOR, MG, 6(1), 12-27.

Alves, A. P., Arpini, D. A., \& Cúnico, S. D. (2015). Guarda compartilhada: perspectivas e desafios diante da responsabilidade parental. Estudos e Pesquisa em Psicologia, 15(3), 916-935.

Badinter, E. (1985). Um amor conquistado: O mito do amor materno. Rio de Janeiro, RJ: Nova Fronteira.

Bardin, L. (2010). Análise de conteúdo. Lisboa: Edições 70.

Brito, L. M. T. (2007). A família pós-divórcio: a visão dos filhos. Psicologia: Ciência e Profissão, 27(1), 32-45. https:// doi.org/10.1590/S1414-98932007000100004

Brito, L. M. T (2004). Guarda conjunta: conceitos, preconceitos e prática no consenso e no litígio. In R. C. Pereira, (Org.). Afeto, ética e o novo Código Civil (pp. 355-367). Anais do Congresso Brasileiro de Direito de Família, Belo Horizonte, 4. Recuperado de http://www.ibdfam.org.br/_img/congressos/anais/122.pdf

Brito, L. M. T. (2003). Igualdade e divisão de responsabilidades: pressupostos e consequências da guarda conjunta. In G. C. Groeninga, \& R. C. Pereira (Org.), Direito de Família e psicanálise: rumo a uma nova epistemologia (pp. 325-337). Rio de Janeiro, RJ: Imago. 
Brito, L. M. T., Cardoso, A. R., \& Oliveira, J. D. G. (2010). Debates entre pais e mães divorciados: um trabalho com grupos. Psicologia: Ciência e Profissão, 30(4) 810-823. https:/doi.org/10.1590/S1414-98932010000400011

Brito, L. M. T., \& Gonsalves, E. N. (2013). Guarda compartilhada: alguns argumentos e conteúdos da jurisprudência. Revista Direito GV, 9(1), 299-318. https://doi.org/10.1590/S1808-24322013000100011

Butler, J. (2003). Problemas de gênero: Feminismo e subversão da identidade. Rio de Janeiro, RJ: Civilização Brasileira.

Cezar-Ferreira, V. A. M., \& Macedo, R. M. S. (2016). Guarda compartilhada: Uma visão psicojurídica. Porto Alegre, RS: Artmed.

Cúnico, S. D. (2014). Significado atribuído à paternidade por mulheres chefes de família de periferia urbana (dissertação). Centro de Ciências Sociais e Humanas, Universidade Federal de Santa Maria, Santa Maria, RS, Brasil.

Cúnico, S. D., \& Arpini, D. M. (2013). O afastamento paterno após o fim do relacionamento amoroso: um estudo qualitativo. Interação Psicologia, 17(1), 99-108.

Dias, M. B. (2015). Manual de direito das famílias (10 ed. rev., atual. ampl.). São Paulo, SP: Revista dos Tribunais.

Fiori, W. R. (1981-1982). Desenvolvimento emocional. In: C. R. Rappaport, W. R. Fiori, \& C. Davis. Psicologia do desenvolvimento: A idade escolar e a adolescência (pp. 01-45). São Paulo, SP: EPU.

Gadoni-Costa, L. M., Frizzo, G. B., \& Lopes, R. C. S. (2015). A guarda compartilhada na prática: Estudo de casos múltiplos. Temas em Psicologia, 23(4), 901-912. https://doi.org/10.9788/TP2015.4-08

Gaglietti, M., Araújo, M. L., \& Gaglietti, N. F. (2015). A mediação de conflitos familiares no contexto do Novo Código de Processo Civil. In C. P. Rosa, \& L. M. B. Thomé (Orgs.), Um presente para construir o futuro: Diálogos sobre família e sucessões (pp. 385-411). Porto Alegre, RS: IBDFAM/RS.

Gaskell, G. (2005). Entrevistas individuais e grupais. In M. W. Bauer, \& G. Gaskell (Orgs.), Pesquisa qualitativa com texto, imagem e som (pp.64-89). Petrópolis, RJ: Vozes.

Godoy, A. S. (1995). Pesquisa qualitativa: Tipos fundamentais. Revista de Administração de Empresas, 35(3), 20-29. https://doi.org/10.1590/S0034-75901995000300004

Golse, B. (2014). Divorce and joint physical custody. Archives Pédiatrie, 21(4), 441-443. https://doi.org/10.1016/j. arcped.2014.01.002

Gomes, R. (2007). Análise e interpretação de dados de pesquisa qualitativa. In M. C. S. Minayo, (Org.), Pesquisa social: Teoria, método e criatividade (pp. 79-108). Petrópolis, RS: Vozes.

Instituto Brasileiro de Geografia e Estatística - IBGE. (2014). Estatística de Registro Civil, 2013: Divórcios concedidos em instância a casais com filhos menores de idade no Brasil. Rio de Janeiro, o autor. Recuperado de https:// ww2.ibge.gov.br/home/estatistica/populacao/registrocivil/2013/default.shtm

Lehmann, R. B. (2013). Facultades y derechos compartidos respecto de los hijos: una mirada desde el derecho comparado. Revista de Derecho, 20(1), 21-60. https://doi.org/10.4067/S0718-97532013000100002

Lei No 8.069, de 13 de julho de 1990. Dispõe sobre o Estatuto da Criança e do Adolescente e dá outras providências. Diário Oficial da União. 27 set. 1990.

Lei $N^{o} 11.698$, de 13 de junho de 2008. Altera os arts. 1.583 e 1.584 da Lei no 10.406, de 10 de janeiro de 2002 - Código Civil, para instituir e disciplinar a guarda compartilhada. Diário Oficial da União, 16 jun. 2008.

Lei $n^{\circ} 13.058$, de 22 de dezembro de 2014. Altera os artigos 1.583, 1.584, 1.585 e 1.634 da lei ${ }^{\circ} 10.406$, de 10 de janeiro de 2002 (Código Civil), para estabelecer o significado da expressão "guarda compartilhada" e dispor sobre sua aplicação. Diário Oficial da União, 24 dez. 2014.

Machado, R. B. (2015). Aspectos da nova Guarda Compartilhada: (Lei $\left.n^{\circ} 13.058,22.12 .2014\right)$. Passos, MG: Gráfica e Editora São Paulo.

Moreira, C. M. S. (2014). A imposição do instituto da guarda compartilhada em contraposição ao princípio do superior interesse da criança (Monografia). Faculdade Ciências Jurídicas e Sociais, Centro Universitário de Brasília, DF, Brasil.

Oliveira, A. L. P. (2015). “Se você ficar com nossos filhos, eu te mato!": Violência doméstica e familiar contra a mulher e as disputas de guarda de filhos/as em trâmite nas Varas de Família de Ceilândia/DF (dissertação). Faculdade de Direito, Universidade de Brasília, Brasília, DF, Brasil. 
Oliveira, L. Z., \& Matos, A. C. H. (2014). Guarda compartilhada e condição feminina: limites e possibilidades para a democratização dos papéis econômicos e afetivo. Pensar, Revista de Ciências Jurídicas, 9(3), 750-778. https://doi. org/10.5020/2317-2150.2014.v19n3p750

Pereira, R. C. (2011). Divórcio: Teoria e prática (3a ed.). Rio de Janeiro, RJ: GZ.

Piaget, J. (2010). Seis estudos de psicologia (24a ed.). Rio de Janeiro, RJ: Forense Universitária.

Projeto de Lei $N^{o}$ 6.315, de 18 de março 2002. Altera dispositivo do Novo Código Civil. Institui a guarda compartilhada dos filhos menores nos termos do acordo celebrado pelos pais. Brasília, DF: Câmara dos Deputados.

Projeto de Lei $N^{o}$ 6.350, de 20 de março de 2002. Define a Guarda Compartilhada. Brasília, DF: Câmara dos Deputados.

Projeto de Lei No 6.960, de 12 de junho de 2002. Dá nova redação a Lei no. 10.406 de 2002, que "Institui o Código Civil", acrescenta dispositivos e dá outras providências. Brasília, DF: Câmara dos Deputados.

Projeto de Lei No 7.312, de 7 de novembro de 2002. Dá nova redação a Lei no 10.406 de 2002, que "Institui o Código Civil" e dá outras providências. Brasília, DF: Câmara dos Deputados.

Resolução No 016, de 20 de dezembro de 2000. Dispõe sobre a realização de Pesquisa em Psicologia com Seres Humanos. Brasília, DF: Conselho Federal de Psicologia.

Resolução No 466, de 12 de dezembro de 2012. Diretrizes e normas regulamentadoras de pesquisas envolvendo seres humanos. Brasília, DF: Ministério da Saúde.

Rosa, C. P. (2015b). Nova lei da guarda compartilhada. São Paulo, SP: Saraiva.

Rosa, C. P. (2015a). A transição do "eu ganhei a guarda" para o compartilhamento da guarda como regra geral: primeiras reflexões sobre a lei 13.058/2014 no direito brasileiro e sua aplicação como meio de prevenção à alienação parental. In C. P. Rosa, \& L. M. B. Thomé (Orgs.), Um presente para construir um futuro: Diálogo sobre a família e sucessões (pp.11-22). Porto Alegre, RS: IBDFAM/RS.

Saffioti, H. I. B. (2001). Contribuições feministas para o estudo da violência de gênero. Cadernos Pagu, (16), 115136. https://doi.org/10.1590/S0104-83332001000100007

Saffioti, H. I. B. (2004). Gênero, patriarcado, violência. São Paulo, SP: Fundação Perseu Abramo.

Sganzerla, I. M., \& Levandowski, D. C. (2010). Ausência paterna e suas repercussões para o adolescente: revisando a literatura. Psicologia em Revista, 16(2), 295-309. https://doi.org/10.5752/P.1678-9563.2010v16n2p295

Sodermans, A. K., \& Matthijs, K. (2014). Joint physical custody and adolescentes' subjective well-being: A personality $\mathrm{x}$ environment interaction. Journal of Family Psychology, 28(3):346-356. https://doi.org/10.1111/j.1741-3737.2010.00723

Tilio, R. (2014). Teorias de Gênero: Principais contribuições teóricas oferecidas pelas perspectivas contemporâneas. Gênero, 14(2), 125-148. https://doi.org/10.22409/rg.v14i2.626

Turato, E. (2003). Tratado de metodologia da pesquisa clínico-qualitativa. Petrópolis, RJ: Vozes.

Yin, R. K. (2005). Estudo de casos: Planejamento e método (3a ed., D. Grassi, trad.). Porto Alegre, RS: Brokman.

\section{Camila Almeida Kostulski}

Psicóloga. Mestre em Psicologia pela Universidade Federal de Santa Maria (UFSM), Santa Maria - RS. Brasil.

E-mail: camila.ak@hotmail.com

\section{Dorian Mônica Arpini}

Docente do Departamento de Psicologia e do Programa de Pós-Graduação em Psicologia da Universidade Federal de Santa Maria (UFSM), Santa Maria - RS. Brasil.

E-mail: monica.arpini@gmail.com

Guarda Compartilhada: Filhas Adolescentes

Rua:Venâncio Aires 1062 ap.03, Santa Maria, RS, Brasil.

CEP: 97010000 
Psicologia: Ciência e Profissão Out/Dez. 2018 v. 38 n4, 696-710.

Recebido 23/03/2017

Reformulado 13/09/2017

Aprovado 19/11/2017

Received $03 / 23 / 2017$

Reformulated $09 / 13 / 2017$

Approved 11/19/2017

Recibido 23/03/2017

Reformulado 13/09/2017

Aceptado 19/11/2017

Como citar: Kostulski, C. A., \& Arpini, D. M. (2018). Guarda compartilhada: as vivências de filhas adolescentes. Psicologia: Ciência e Profissão, 38(4), 696-710. https://doi.org/10.1590/1982-3703000972017

How to cite: Kostulski, C. A., \& Arpini, D. M. (2018). Joint custody: the experiences of teenage daughters. Psicologia: Ciência e Profissão, 38(4), 696-710. https://doi.org/10.1590/1982-3703000972017

Cómo citar: Kostulski, C. A., \& Arpini, D. M. (2018). Custodia compartida: las vivencias de hijas adolescentes. Psicologia: Ciência e Profissão, 38(4), 696-710. https://doi.org/10.1590/1982-3703000972017 